\section{Isolation and Performance Study of a Novel Lignin-degrading Strain}

\author{
W. Zhang ${ }^{\mathrm{a}, *}$ and Z. Liu \\ ${ }^{a}$ College of Biology and Environmental Engineering, \\ Zhejiang Shuren University, Hangzhou 310015, China \\ ${ }^{\mathrm{b} C}$ College of Environment and Chemistry Engineering, \\ Yanshan University, Qinhuangdao 066004, China
}

\author{
doi: https://doi.org/10.15255/CABEQ.2021.1939 \\ Original scientific paper \\ Received: March 1, 2021 \\ Accepted: September 29, 2021
}

The degradation of lignin cannot only reduce the impact of lignin pollutants on the environment, but it can also help to realize the efficient utilization of biomass resources. Obtaining the efficient lignin-degrading strain is necessary for the application of lignin biological degradation treatment. In this study, a novel lignin-degrading strain M01-L2 was isolated from a forest park in eastern China. The sequencing results showed that the M01-L2 strain was Burkholderia sp. H801. The kraft lignin degradation experiments showed that the lignin degradation efficiency of M01-L2 reached $49.8 \%$ on the sixth day with the initial lignin concentration of $1 \mathrm{~g} \mathrm{~L} \mathrm{~L}^{-1}$. This degradation process was carried out in the medium with lignin as the only carbon source. The lignin degradation process by M01-L2 strain mainly depended on the action of Lac and MnP enzymes. The MnP activity was maintained at a high level and increased significantly in the first four days, and the maximum value was $1544.4 \mathrm{U} \mathrm{L}^{-1}$. Lac enzyme activity increased significantly from the third day to the sixth day, reaching $757.9 \mathrm{U} \mathrm{L}^{-1}$ on the sixth day. This study can provide a new method for bacterial degradation of lignin.

Keywords:

lignin degradation, Kraft lignin, Lac, MnP

\section{Introduction}

The complicated aromatic polymer lignin, which widely exists in various higher plants (including ferns, but not in liverworts and mosses), is the most abundant renewable aromatic resources in Earth's biosphere ${ }^{1}$. Lignin is associated with cellulose and hemicellulose, and can form a physical and impenetrable seal in the plant cell. Lignin present in the cell wall can give plant its structural support, impermeability, and resistance against microbial attack $^{2}$. Lignin can be divided into three basic structures: hydroxyphenyl lignin from the polymerization of $p$-hydroxyphenyl propane monomer, guajacyl lignin from the polymerization of guaiacyl propane monomers, and syringyl lignin polymerized from syringyl propane monomers ${ }^{3,4}$. These three basic structures can be linked irregularly, thus forming the extremely complex molecular structure of lignin ${ }^{5}$. The complicated aromatic polymer structure makes lignin hard to degrade ${ }^{6}$.

Although lignin degradation is difficult, its degradation can bring the following beneficial effects. The degradation of lignin can improve the

"Corresponding author: Tel/fax: + 86057188297098 (Wen Zhang)

E-mail address: gillianjay@126.com (Wen Zhang) pretreatment effect of lignocellulosic biomass, and help to realize the efficient transformation of biomass to bioenergy and other industrial products? Meanwhile, lignin degradation, especially complete biodegradation, can help solve the environmental problems caused by lignin pollutant emission or incineration $^{8,9}$. In addition, the lignin degradation can produce aromatic industrial products with high added value. Lignin degradation can bring great economic and ecological benefits.

The degradation methods of lignin encompass chemical, physical, and biological processes. The biodegradation method is environmentally friendly and with low energy consumption. The most active microbes with respect to lignin degradation identified to date are fungi, such as those belonging to the white-rot families ${ }^{10}$. In nature, phenol oxidases, including lignin peroxidase (LiP), manganese peroxidase (MnP), and laccase (Lac), are secreted by white-rot fungi and are assumed to degrade lignin ${ }^{11}$ initially. At present, fungi for lignin degradation include Lenzites betulinus ${ }^{12}$, Penicillium chrysogenum $^{13}$, Cladosporium ${ }^{14}$ and Phanerochaete chrysosporium ${ }^{15}$, among which Phanerochaete chrysosporium has a strong ability to degrade lignin, and has become a model strain for lignin degradation research. However, these microorganisms often lack 
the traits required for industrial application, such as high growth efficiency and strong environmental adaptability ${ }^{16}$. The bacteria grow fast and can tolerate a wide range of temperature, $\mathrm{pH}$, and dissolved oxygen concentration. Meanwhile, some research has proved that the bacterial degradation of lignin can produce high value-added metabolites, which have changed the opinion that compared to the chemical method, the biodegradation method cannot yield chemicals with industrial application val$\mathrm{ue}^{17}$. Kumar et al. ${ }^{18}$ reported that Pandoraea sp. ISTKB can degrade lignin to ferulic acid. Bacillus sp. can degrade lignin to produce a variety of products, including ferulic acid, cinnamic acid, vanillic acid, and 3,4,5-trimethoxybenzaldehyde ${ }^{19}$. Bacterial degradation of lignin has these obvious advantages, but the lignin degradation efficiency of bacterial degradation still needs to be improved, and the yield of high value-added products is always low, which limits the application potential of bacterial degradation of $\operatorname{lignin}^{20}$. Therefore, further research is needed to continuously explore more efficient lignin degrading bacterial resources and promote the application of lignin degrading bacteria in different lignin degradation systems.

In this study, an efficient lignin degradation bacterium was screened from nature. At the same time, the process of lignin degradation by the strain was further studied. Firstly, the conditions of lignin degradation by the strain were studied, and the key factors affecting the degradation were determined. Then, under the optimal degradation conditions, the lignin degrading enzymes of the strain were analyzed to study the metabolism mechanism of lignin. This study can provide a new method for the bacterial degradation of lignin.

\section{Materials and methods}

\section{Materials}

All chemicals of analytical reagent grade were purchased from Nanjing Reagent Factory (Nanjing, China). The biochemical reagents were produced by Beijing Biological Technology Factory (Beijing, China). The Kraft lignin (KL, molecular weight of approximately 10,000) used in these experiments was purchased from Sigma Aldrich (St. Louis, MO, USA). The isolated strains were stored in the tube culture (solid activation culture medium) at $4{ }^{\circ} \mathrm{C}$ (refrigerator). The soil samples for the isolation experiments were collected from Xishan Forest Park (Hangzhou, China). When sampling, the soil covered by dead branches and rotten bark in the forest was chosen.

\section{Culture media and microorganism culture}

The composition of the activation medium was as follows: tryptone $10 \mathrm{~g} \mathrm{~L}^{-1}$, yeast extract $5 \mathrm{~g} \mathrm{~L}^{-1}$, and $\mathrm{NaCl} 10 \mathrm{~g} \mathrm{~L}^{-1}$. The solid activation medium was prepared by adding $15 \mathrm{~g} \mathrm{~L}^{-1}$ agar to the activation culture medium. The composition of the enrichment medium was as follows: lignin $1 \mathrm{~g} \mathrm{~L}^{-1}$, $\left(\mathrm{NH}_{4}\right)_{2} \mathrm{SO}_{4} 2 \mathrm{~g} \mathrm{~L}^{-1}, \mathrm{~K}_{2} \mathrm{HPO}_{4} 1 \mathrm{~g} \mathrm{~L}^{-1}, \mathrm{KH}_{2} \mathrm{PO}_{4} 1 \mathrm{~g} \mathrm{~L}^{-1}$, $\mathrm{CaCl}_{2} 0.1 \mathrm{~g} \mathrm{~L}^{-1}, \mathrm{MgSO}_{4} 0.2 \mathrm{~g} \mathrm{~L}^{-1}, \mathrm{FeSO}_{4} 0.05 \mathrm{~g} \mathrm{~L}^{-1}$ and $\mathrm{MnSO}_{4} 0.02 \mathrm{~g} \mathrm{~L}^{-1}$. The solid enrichment medium was prepared by adding $15 \mathrm{~g} \mathrm{~L}^{-1}$ agar to the enrichment medium. The composition of the aniline blue decolorization medium was as follows: yeast extract $10 \mathrm{~g} \mathrm{~L}^{-1}$, glucose $20 \mathrm{~g} \mathrm{~L}^{-1}$, aniline blue $0.1 \mathrm{~g} \mathrm{~L}^{-1}$ and agar $15 \mathrm{~g} \mathrm{~L}^{-1}$. All media were sterilized $\left(121^{\circ} \mathrm{C}\right.$, $30 \mathrm{~min}$ ) before use.

\section{Isolation of lignin degradation bacteria}

Different soil samples were collected. An amount of $5 \mathrm{~g}$ of soil was then added to the enrichment medium, cultured at $30^{\circ} \mathrm{C}, 120 \mathrm{rpm}$ for $48 \mathrm{~h}$. The suspension was then inoculated into a new enrichment medium. The microorganism was cultured for another $48 \mathrm{~h}$. If the color of the medium became lighter, the suspension was inoculated into the new medium, and continued to culture for $48 \mathrm{~h}$. The enriched culture medium was diluted by sterile water to obtain $10^{-3}, 10^{-4}$ and $10^{-5}$ dilutions, then the dilutions were inoculated on the aniline blue decolorization medium. The cultivation was carried out in a biochemical incubator at $30^{\circ} \mathrm{C}$, and the change in the colony color was observed. The colony with transparent ring on the aniline blue decolorization medium was inoculated and purified on the solid enrichment medium (plate streaking) and cultured in a biochemical incubator at $30{ }^{\circ} \mathrm{C}$. The purified single colony was inoculated to the aniline blue decolorization medium by an inoculating loop. The diameter of the decolorizing circle was measured with caliper and compared among the isolated microorganisms. The strains with larger diameter of decolorizing circle were selected as the research strains for lignin degradation experiment, and the strain with the highest degradation efficiency was selected as the follow-up experimental strain. The genomic DNA of this strain was extracted by precipitation method ${ }^{21}$. The automatic sequencing was carried out by Beijing Sun Biotech Co., Ltd. The 16S rDNA sequence was checked in GenBank.

\section{Lignin degradation process}

The conditions of lignin degradation using high-efficiency lignin degrading bacteria were optimized on a shake-flask scale. Firstly, the isolated strain stored in the refrigerator was cultured in the activation medium at $32{ }^{\circ} \mathrm{C}$ and $120 \mathrm{rpm}$ for $48 \mathrm{~h}$ to 
form the seed liquid. The liquid containing suspended cells was then transferred to enrichment medium $(100 \mathrm{~mL})$ for lignin degradation experiments in a $250-\mathrm{mL}$ flask. All the lignin degradation experiments were carried on a shaking incubator with a rotational radius of $10 \mathrm{~cm}$. The control experiments were set in the same operating mode without adding microorganisms. Their results showed that lignin concentration remained unchanged.

\section{Culture temperature}

The strain was inoculated with $5 \%$ inoculation amount in the enrichment medium with lignin concentration of $1 \mathrm{~g} \mathrm{~L}^{-1}$, shaking speed of $120 \mathrm{rpm}$, and $\mathrm{pH}$ of 7. The strain was cultured at $25^{\circ} \mathrm{C}, 30^{\circ} \mathrm{C}, 35^{\circ} \mathrm{C}$, and $40{ }^{\circ} \mathrm{C}$, respectively for 7 days. The degradation efficiency of lignin was measured regularly every day to obtain the optimum culture temperature.

$\mathrm{pH}$

The strain was inoculated with $5 \%$ inoculation amount in the enrichment medium with lignin concentration of $1 \mathrm{~g} \mathrm{~L}^{-1}$, shaking speed of $120 \mathrm{rpm}$, and $\mathrm{pH}$ of $5,6,7,8$, and 9 , respectively. The degradation experiments were carried out at optimum temperature (obtained from the previous experiment) for 7 days. The lignin degradation efficiency was measured regularly every day to obtain the optimum culture $\mathrm{pH}$.

\section{Inoculation amount}

The strain was inoculated with different inoculation amounts of $1 \%, 5 \%, 10 \%$, and $15 \%$, respectively. The shaking speed was $120 \mathrm{rpm}$. The degradation experiments were carried out at the optimum temperature and $\mathrm{pH}$ (obtained from the previous experiments) for 7 days. The degradation efficiency of lignin was measured regularly every day to obtain the optimum inoculation amount.

\section{Shaking speed}

The strain was inoculated with the optimum inoculation amount into the enrichment medium with different shaking speeds of $80,120,160$, and 200 $\mathrm{rpm}$, respectively. The degradation experiments were carried out at the optimum temperature, $\mathrm{pH}$, and inoculation amount (obtained from the previous experiments) for 7 days. The degradation efficiency of lignin was measured regularly every day to obtain the optimum shaking speed.

\section{Lignin concentration}

The strain was inoculated with the optimum inoculation amount into the enrichment medium with different lignin concentrations of $0.5,1.0,1.5$, and
$2.0 \mathrm{~g} \mathrm{~L}^{-1}$, respectively. The degradation experiments were carried out at optimum temperature, shaking speed, inoculation amount, and $\mathrm{pH}$ (obtained from the previous experiments) for 7 days. The degradation efficiency of lignin was measured regularly every day.

\section{Lignin degradation enzyme}

The lignin degradation experiment was carried out under the aforementioned optimal conditions, and the activity of lignin degradation enzyme was detected. The culture medium sampled at different times (days 1 to 7 ) was placed in the centrifuge tubes, and then centrifuged $(4024.8 \times \mathrm{g}, 10 \mathrm{~min}$; Frontier $^{\mathrm{TM}} 5000$ Multi Pro, OHAUS, USA) to remove the cells. The activities of laccase, lignin peroxidase and manganese peroxidase were measured in the supernatant. Laccase activity was determined by monitoring the oxidation of $2,2^{\prime}$-azinobis(3-ethylbenzthiazoline-6-sulfonate) at $420 \mathrm{~nm}^{22}$. The activity of lignin peroxidase was determined by monitoring the oxidation of $2 \mathrm{mM}$ veratryl alcohol to veratraldehyde at $310 \mathrm{~nm}^{23}$. The activity of manganese peroxidase was determined by monitoring the oxidation of 2,6-dimethoxyphenol to coerulignone at $469 \mathrm{~nm}^{24}$.

\section{Analytical methods}

The strain growth was determined by measuring the OD600 of cultured samples ${ }^{25}$ using a visible spectrophotometer (DR3900, HACH, USA). The lignin concentration was measured by an ultraviolet spectrophotometer (UV-2700i, Shimadzu, Japan) at $280 \mathrm{~nm}^{26}$. The lignin degradation efficiency was calculated as follows:

Degradation efficiency of lignin $(\%)=$ (initial lignin concentration - lignin concentration after treatment) / initial lignin concentration.

\section{Statistical methods}

Three parallel samples were set and the average degradation efficiency was calculated as the final value. One-way ANOVA with Tukey's test was used to detect the significant influencing factors during lignin degradation process $(P<0.05)$.

\section{Results and discussion}

\section{Isolation of lignin degradation bacteria}

According to methods proposed in Section "Isolation of lignin degradation bacteria", six lignin degrading bacteria were screened from ten samples, which could decolor the aniline blue medium. Lignin degrading bacteria can degrade lignin by producing laccase. Laccase is a kind of polyphenol oxidase. 
Table 1 - Measurement of discoloration circle diameter

\begin{tabular}{c|c|c|c|c|c|c}
\hline $\begin{array}{c}\text { Time } \\
(\text { day })\end{array}$ & $\begin{array}{c}\text { M01-L1 } \\
(\mathrm{cm})\end{array}$ & $\begin{array}{c}\text { M01-L2 } \\
(\mathrm{cm})\end{array}$ & $\begin{array}{c}\text { M01-L3 } \\
(\mathrm{cm})\end{array}$ & $\begin{array}{c}\text { M01-L4 } \\
(\mathrm{cm})\end{array}$ & $\begin{array}{c}\text { M01-L5 } \\
(\mathrm{cm})\end{array}$ & $\begin{array}{c}\text { M01-L6 } \\
(\mathrm{cm})\end{array}$ \\
\hline 1 & 0 & 0 & 0 & 0 & 0 & 0 \\
2 & 1.82 & 1.67 & 1.55 & 1.60 & 1.87 & 1.46 \\
3 & 1.96 & 1.94 & 1.84 & 1.70 & 1.95 & 1.50 \\
4 & 2.43 & 2.37 & 2.10 & 2.00 & 2.16 & 1.76 \\
5 & 2.47 & 2.93 & 2.83 & 2.18 & 2.75 & 1.95 \\
6 & 2.51 & 3.45 & 3.34 & 2.65 & 2.88 & 2.00 \\
7 & 2.53 & 3.53 & 3.41 & 2.75 & 2.95 & 2.14 \\
8 & 2.54 & 3.53 & 3.42 & 2.77 & 3.00 & 2.14 \\
\hline
\end{tabular}

With the breaking of aniline blue polyphenol bond, aniline blue is degraded and blue color disappears. After purification, the six strains were cultured. The purified bacteria were then inoculated on aniline blue medium again, and the diameters of the decolorizing circle were measured regularly every day. The results are shown in Table 1. The discoloring circle diameter of M01-L2 was maximum, which represented the highest enzyme production and the best lignin degradation effect. Strain M01-L2 was chosen for further experiments. The sequencing results showed that the strain M01-L2 was $99 \%$ identical to Burkholderia sp. H801 (Accession No. AB212238.1). The phylogenetic tree is shown in Fig. 1. The isolated lignin-degrading strain was a member of Burkholderia genus.

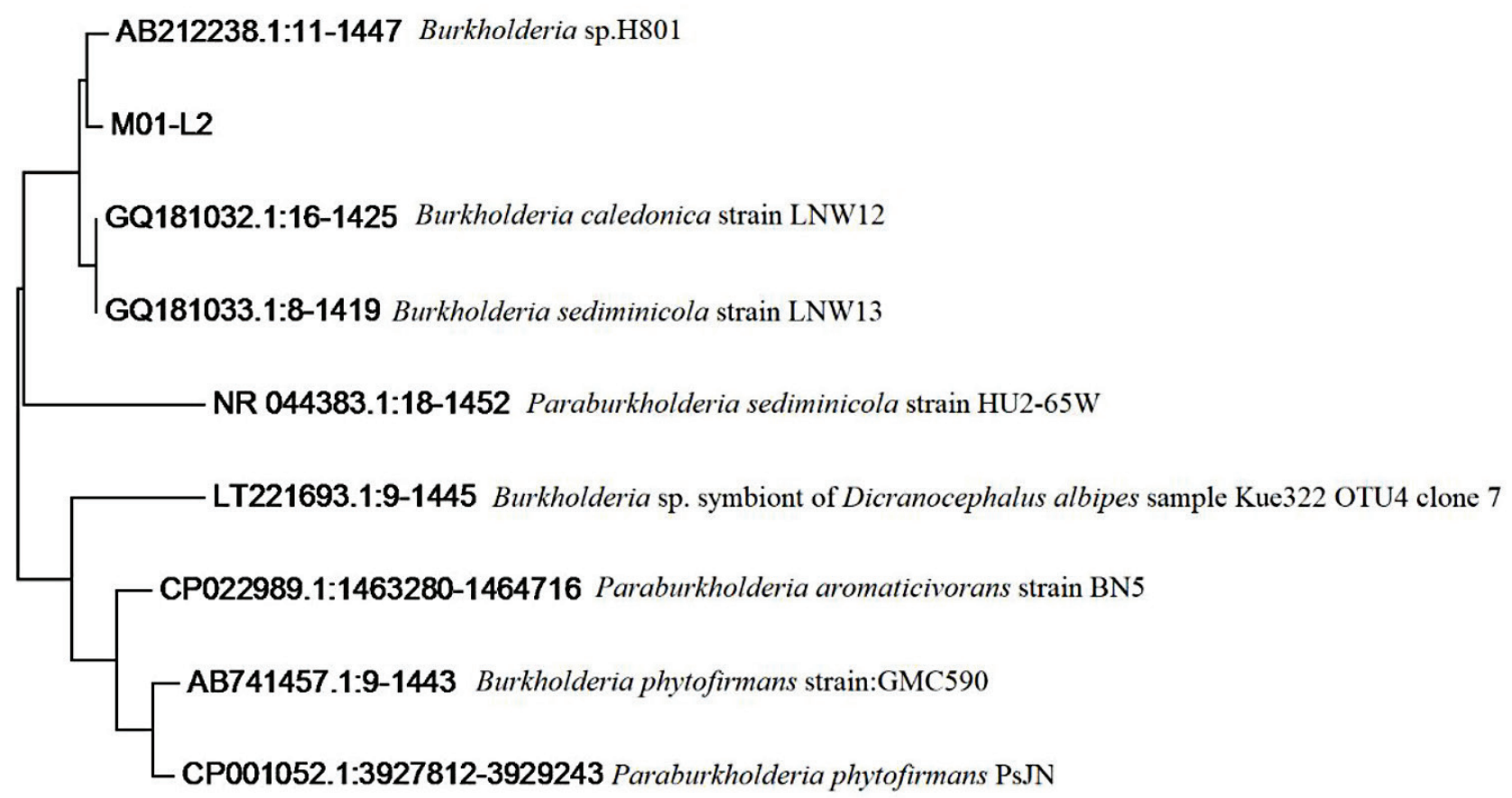

\section{Degradation of lignin by strain M01-L2}

In the degradation experiments, according to the reports of other literature ${ }^{18,25}$, the residual lignin concentration was measured every day for 7 days to calculate the degradation efficiency of lignin. In this study, by changing the degradation conditions, the optimum parameters of lignin degradation were obtained, and the main factors affecting the degradation of lignin degradation bacteria were analyzed.

\section{Effect of temperature on lignin degradation}

To reduce the energy consumption of the degradation process, the degradation experiments are generally carried out at about room temperature. If the lignin degradation efficiency of the microorganism at room temperature is higher, the microorganism has more potential in practical application. The range of degradation temperature selected in this study was from $20{ }^{\circ} \mathrm{C}$ to $40{ }^{\circ} \mathrm{C}$, all of which were near room temperature. The effect of temperature on degradation process is shown in Fig. 2. The temperature most suitable for microbial growth and organic matter degradation has always been considered to be $30{ }^{\circ} \mathrm{C}^{27}$. However, in this study, $35^{\circ} \mathrm{C}$ was better, and the degradation efficiency of lignin on the sixth day reached $47.1 \%$. When the treatment temperature was $40{ }^{\circ} \mathrm{C}$, the degradation efficiency of lignin decreased to some extent, which is similar to that of the bacteria reported in the literature $^{28,29}$. 


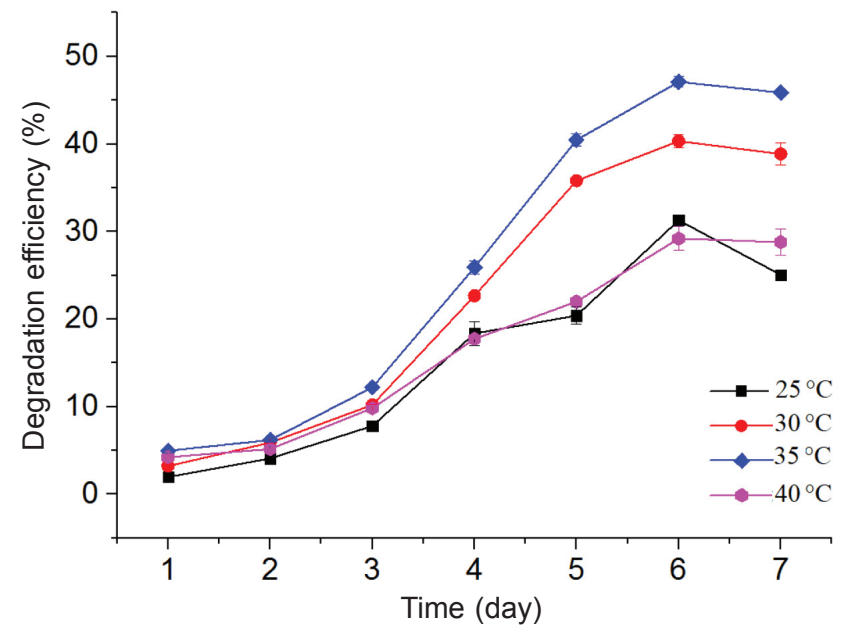

Fig. 2 - Effect of temperature on lignin degradation (initial lignin concentration $=1 \mathrm{~g} \mathrm{~L}^{-1}$, shaking speed $=120$ rpm, $p H=7$, inoculation amount $=5 \%$ )

\section{Effect of $\mathrm{pH}$ on lignin degradation}

For the lignin degradation, $\mathrm{pH}$ is a key factor ${ }^{30}$. Under the optimum temperature, the influence of the substrate $\mathrm{pH}$ value on lignin degradation was investigated, as shown in Fig. 3. In the range of $\mathrm{pH}$ $7-8$, the degradation efficiency of lignin was higher, which is very close to that of other reported lignin degradation bacteria, e.g., the optimal pH of Aneurinibacillus aneurilyticus was $7.6^{31}$, and the optimal $\mathrm{pH}$ of Comasonas sp. B-9 was $7^{32}$. The adaptability of the lignin degrading bacteria was better under neutral conditions. Statistical analysis showed that temperature had a significant effect on the lignin degradation efficiency $(P<0.05)$. In addition, the degradation of lignin was decreased under acid conditions, because the $\mathrm{pH}$ which is suitable for bacteria growth is often neutral ${ }^{30}$.

\section{Effect of inoculation amount on lignin degradation}

In this section, the effect of inoculation amount on lignin degradation by strain M01-L2 was also analyzed. The inoculation amount ranged from $1 \%$ to $15 \%$, and the degradation efficiency was calculated every day. The results are shown in Fig. 4. The degradation efficiency was the highest when the inoculation amount was $5 \%$. The growth of bacteria is fast, so the effect of inoculation amount on lignin degradation is relatively small. Inoculation amount is never the most important factor ${ }^{33}$. Under a certain amount of inoculation, bacteria can grow and propagate rapidly. However, when the inoculum amount is too large, the lack of dissolved oxygen in the system may finally affect the degradation process of lignin. This also explains why the degradation efficiency of lignin was significantly reduced when the inoculation amount reached $15 \%$.

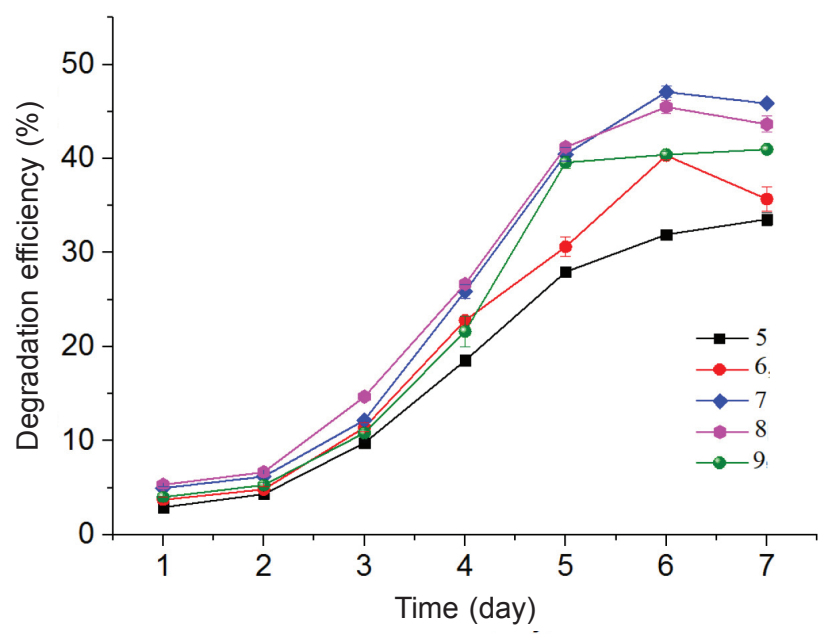

Fig. 3 - Effect of pH on lignin degradation (initial lignin concentration $=1 \mathrm{~g} \mathrm{~L} \mathrm{~L}^{-1}$, shaking speed $=120 \mathrm{rpm}$, temperature $=35^{\circ} \mathrm{C}$, inoculation amount $=5 \%$ )

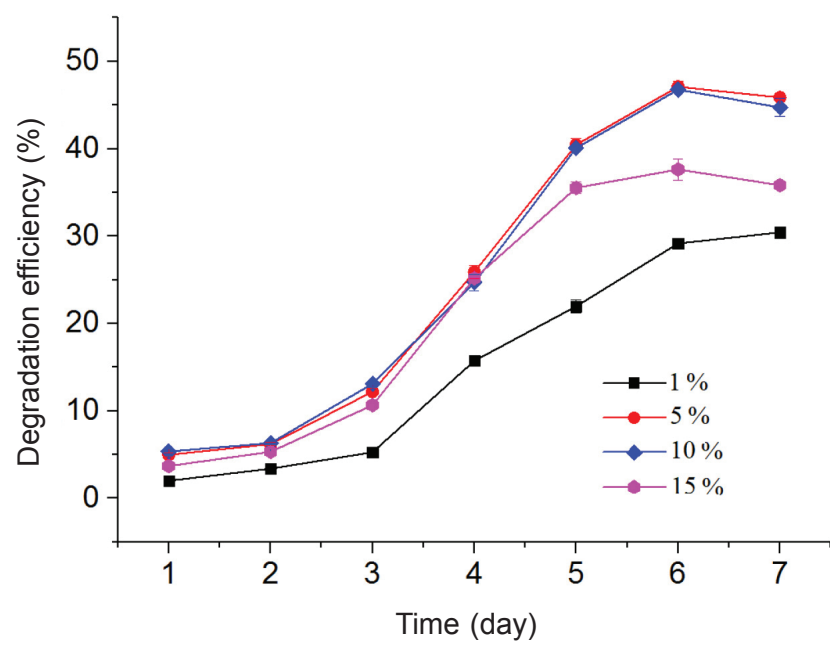

Fig. 4 - Effect of inoculation amount on lignin degradation (initial lignin concentration $=1 \mathrm{~g} \mathrm{~L}^{-1}$, shaking speed $=120 \mathrm{rpm}$, temperature $=35^{\circ} \mathrm{C}, \mathrm{pH}=7$ )

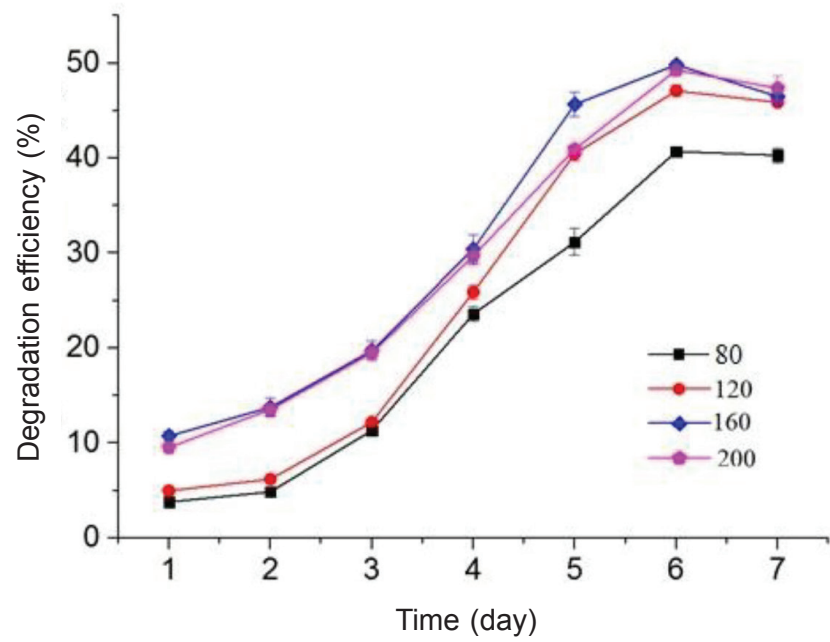

Fig. 5 - Effect of shaking speed on lignin degradation (initial lignin concentration $=1 \mathrm{~g} \mathrm{~L}^{-1}$, inoculation amount $=5 \%$, temperature $=35^{\circ} \mathrm{C}, \mathrm{pH}=7$ ) 
Effect of shaking speed on lignin degradation

Aerobic bacteria need oxygen to participate in the degradation process, and the shaking speed is related to the concentration of oxygen in the solution. Shaking is also conducive to mass transfer. In this study, different shaking speeds were selected to degrade lignin. The results (Fig. 5) showed that the degradation efficiency of lignin had improved with the increase in shaking speed. However, the degradation efficiency of lignin was almost the same at $160 \mathrm{rpm}$ and $200 \mathrm{rpm}$. To reduce energy consumption, in the follow-up study, $160 \mathrm{rpm}$ was selected as the shaking speed.

\section{Effect of initial lignin concentration on lignin degradation}

Under the aforementioned optimal conditions, the degradation of lignin degrading bacteria was analyzed by changing the initial lignin concentration, as shown in Fig. 6. The lignin degradation bacteria in this study reached the optimal degradation effect when the lignin concentration was $1 \mathrm{~g} \mathrm{~L}^{-1}$. In the range of the lignin concentration studied, the lowest degradation effect was also up to $31 \%$. Moreover, the degradation of lignin can be realized without adding other carbon sources, which is similar to other bacteria reported in the literature ${ }^{28}$. It also showed that the isolated lignin degrading bacteria could be used in different lignin degradation systems. In addition, the biomass (OD600) under different lignin concentrations was tested, as shown in Fig. 7. When the lignin concentration increased to 2 $\mathrm{g} \mathrm{L}^{-1}$, the biomass decreased significantly. If the concentration of lignin is too high, lignin can inhibit the growth of microorganisms.

In summary, the Kraft lignin degradation experiments showed that the lignin degradation efficiency of M01-L2 reached $49.8 \%$ on the sixth day with the initial lignin concentration of $1 \mathrm{~g} \mathrm{~L}^{-1}$. Compared with other bacteria, the degradation efficiency of lignin $\left(0.5 \mathrm{~g} \mathrm{~L}^{-1}\right)$ by bacteria Cupriavidus basilensis B-8 was $38 \%$ at day $7^{28}$. The degradation efficiency of lignin $\left(0.4 \mathrm{~g} \mathrm{~L}^{-1}\right)$ by Bacillus flexus was $20 \%$ at day $9^{29}$. Compared with fungi, the degradation efficiency of lignin $\left(2.0 \mathrm{~g} \mathrm{~L}^{-1}\right)$ by Cladosporium sp. Bio-1 was $35 \%$ at day $10^{34}$. The degradation rate of lignin $(0.5 \%)$ by Phellinus sp was $36 \%$ at day $10^{35}$. Therefore, the bacteria isolated in this research have a strong application prospect.

At the same time, the $\mathrm{pH}$ value of the system had a greater impact on the degradation of lignin, and the degradation effect of the bacteria was better under neutral conditions. When the concentration of lignin was high, the degradation efficiency of lignin decreased. The reason was that the increase of lignin concentration affected the growth of bacteria.

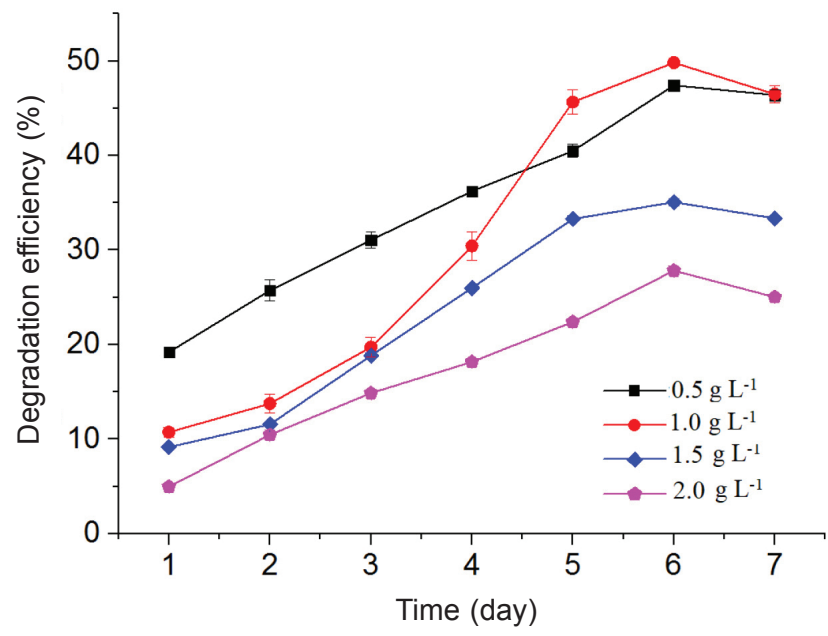

Fig. 6 - Effect of initial lignin concentration on lignin degradation (shaking speed $=160 \mathrm{rpm}$, inoculation amount $=5 \%$, temperature $=35^{\circ} \mathrm{C}, \mathrm{pH}=7$ )

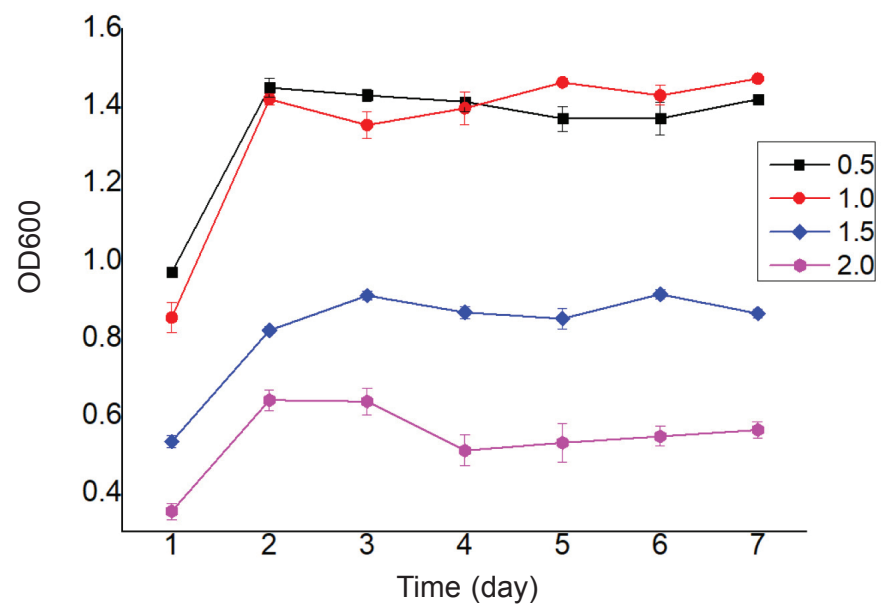

Fig. 7 - The biomass (OD600) under different lignin concentrations

\section{Analysis of enzymes related to lignin degradation}

To study the degradation mechanism of lignin, the lignin degradation experiment was carried out under the aforementioned optimal conditions, and the activity of lignin degradation enzyme was detected at different times. The three main enzymes of lignin degradation in microorganisms include LiP, $\mathrm{MnP}$ and Lac. LiP and MnP oxidize the substrate by two successive single electron oxidation steps ${ }^{35}$. LiP degrades the non-phenol lignin units, while MnP generates $\mathrm{Mn}^{3+}$, which acts as a diffusion oxidant on the phenol lignin or non-phenol lignin units through lipid peroxidation ${ }^{36}$. Laccase is a blue copper oxidase that catalyzes the single electron oxidation of phenols and other electron rich substrates ${ }^{37}$.

The activity changes of these three enzymes in the degradation process are shown in Fig. 8. MnP activity remained at a high level and increased sig- 


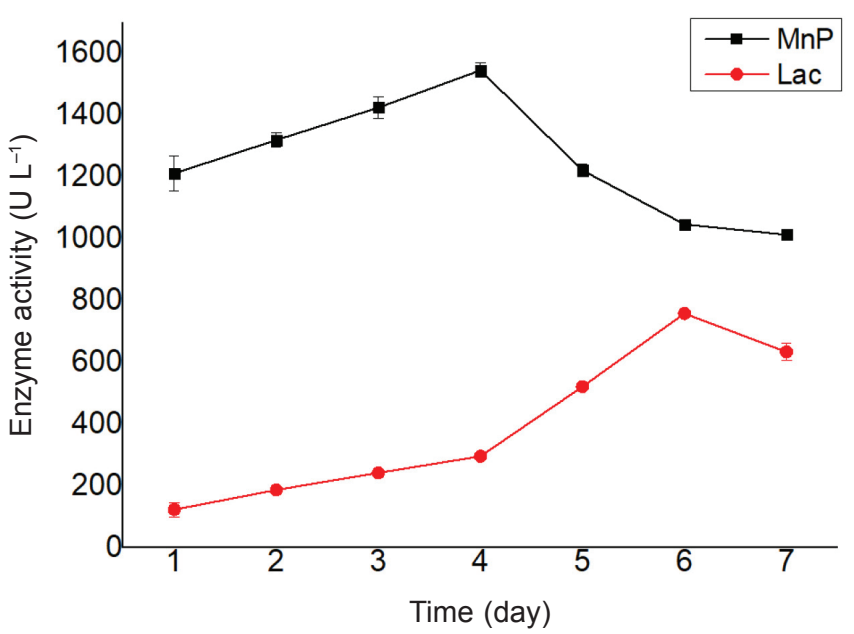

Fig. 8 - The enzymes activity changes in the degradation process

nificantly in the first four days, with a maximum of 1544.4 $\mathrm{U} \mathrm{L} \mathrm{L}^{-1}$ on the fourth day. Then, from the fourth day, the enzyme activity decreased to a certain extent, and on the seventh day of the reaction, the enzyme activity decreased to $1012.3 \mathrm{U} \mathrm{L}^{-1}$. Lac enzyme activity increased significantly from the third day to the sixth day, and reached $757.9 \mathrm{U} \mathrm{L}^{-1}$ on the sixth day. This was also related to the degradation efficiency of lignin in our previous study, which reached the maximum on the sixth day. At the same time, these results also showed that MnP and Lac worked together in the whole process of lignin degradation, $\mathrm{MnP}$ enzyme started to work first, then Lac enzyme gradually worked later. In addition, LiP was not detected in the reaction process, which was similar to other bacteria reported in the literature ${ }^{28}$. However, the existence of these two enzymes makes the microorganism have a strong degradation effect on lignin, especially soluble lignin, so in the treatment of wastewater containing lignin, this kind of bacteria can achieve good treatment effect.

\section{Conclusion}

In this study, lignin degrading bacteria were screened from the soil of the Xishan Forest Park (Hangzhou, China). Strain M01-L2 was chosen for further experiments. The sequencing results showed M01-L2 was $99 \%$ identical to Burkholderia sp. H801 (Accession No. AB212238.1). The Kraft lignin degradation experiments showed that the maximum lignin degradation efficiency of M01-L2 reached $49.8 \%$ on the sixth day. The lignin degradation efficiency of M01-L2 was higher than that of many microorganisms reported in the references. After studying the degradation characteristics of strain M01-L2, it was found that $\mathrm{pH}$ value of the system had a significant impact on the degradation of lignin, and the degradation effect of the bacteria was better under neutral conditions. In addition, it was found that the lignin degradation process mainly depended on the action of two enzymes, Lac and MnP. However, to study the degradation mechanism more thoroughly, the degradation products need to be further analyzed in future research.

\section{ACKNOWLEDGEMENTS}

The authors gratefully acknowledge the support from Natural Science Foundation of Zhejiang Province (LQ20B060004) and Zhejiang Shuren University project (2019R017; 2020XZ010).

\section{References}

1. Bugg, T. D. H., Williamson, J. J., Rashid, G. M. M., Bacterial enzymes for lignin depolymerisation: New biocatalysts for generation of renewable chemicals from biomass, Curr. Opin. Chem. Biol. 55 (2020) 26. doi: https://doi.org/10.1016/j.cbpa.2019.11.007

2. Kamimura, N., Sakamoto, S., Mitsuda, N., Masai, E., Kajita, S., Advances in microbial lignin degradation and its applications, Curr. Opin. Biotech. 56 (2019) 179. doi: https://doi.org/10.1016/j.copbio.2018.11.011

3. Diana, Y., Veronika, D., Tony, M. C., Stefan, R., Michael, L., Philipp, B., Isolation, identification and characterization of lignocellulolytic aerobic and anaerobic fungi in one- and two-phase biogas plants, Bioresour. Technol. 268 (2018) 470 .

doi: https://doi.org/10.1016/j.biortech.2018.07.103

4. Catucci, G., Valetti, F., Sadeghi, S. J., Gilardi, G., Biochemical features of dye-decolorizing peroxidases: Current impact on lignin degradation, Appl. Biochem. Biotech. 67 (2020) 751 .

doi: https://doi.org/10.1002/bab.2015

5. Zhu, C., Wan, C. X., Biological valorization strategies for converting lignin into fuels and chemicals, Renew. Sust. Energ. Rev. 73 (2017) 610. doi: https://doi.org/10.1016/j.rser.2017.01.166

6. Lv, Y., Chen, Y., Sun, S., Hu, Y., Interaction among multiple microorganisms and effects of nitrogen and carbon supplementations on lignin degradation, Bioresour. Technol. 155 (2014) 144. doi: https://doi.org/10.1016/j.biortech.2013.12.012

7. Zhao, C., Xie, S., Pu, Y., Zhang, R., Huang, F., Ragauskas, A. J., Yuan, J. S., Synergistic enzymatic and microbial lignin conversion, Green Chem. 18 (2016) 1306. doi: https://doi.org/10.1039/C5GC01955A

8. Chang, Y. C., Choi, D., Takamizawa, K., Isolation of Bacillus sp. strains capable of decomposing alkali lignin and their application in combination with lactic acid bacteria for enhancing cellulase performance, Bioresour. Technol. 152 (2014) 429. doi: https://doi.org/10.1016/j.biortech.2013.11.032

9. Wang, R. Z., You, T. T., Yang, G. H., Xu, F., Efficient short time white rot- brown rot fungal pretreatments for the enhancement of enzymatic saccharification of corn cobs, ACS Sustain. Chem. Eng. 5 (2017) 10849.

doi: https://doi.org/10.1021/acssuschemeng.7b02786 
10. Haselwandter, K., Bobleter, O., Read, D. J., Degradation of 14C-labelled lignin and dehydropolymer of coniferyl alcohol by ericoid and ectomycorrhizal fungi, Arch. Microbiol. 153 (1990) 352. doi: https://doi.org/10.1007/BF00249004

11. Kuhad, R. C., Singh, A., Ericsson, K. E. L., Microorganisms and enzymes involved in the degradation of plant fiber cell walls, Adv. Biochem. Eng. Biotechnol. 57 (1997) 45. doi: https://doi.org/10.1007/BFb0102072

12. Adejoye, Q. D., Fasidi, I. O., Biodegradation of agro-wastes by some Nigerian white-rot fungi, Bioresour. 4 (2009) 816. doi: https://doi.org/10.1007/s10086-009-1028-2

13. Rodríguez, A., Carnicero, A., Perestelo, F., De Fuente, G., Milstein, O., Falcón, M. A., Effect of Penicillium chrysogenum on lignin transformation, Appl. Environ. Microbiol. 60 (1994) 2971. doi: https://doi.org/10.1002/bit.260440418

14. Jin, R., Liao, H., Liu, X., Zheng, M., Xiong, X., Identification and characterization of a fungal strain with lignin and cellulose hydrolysis activities, Afr. J. Microbiol. Res. 6 (2012) 6545. doi: https://doi.org/10.5897/AJMR12.476

15. Ulmer, D. C., Leisola, M. S. A., Schmidt, B. H., Fiechter, A., Rapid degradation of isolated lignins by Phanerochaete chrysosporium, Appl. Environ. Microbiol. 45 (1983) 1795. doi: https://doi.org/10.1016/0005-2728(84)90100-2

16. Zhang, W., Ren, X., Lei, Q., Wang, L., Screening and comparison of lignin degradation microbial consortia from wooden antiques, Molecules 26 (2021) 2862. doi: https://doi.org/10.1016/10.3390/molecules26102862

17. Mycroft, Z., Gomis, M., Mines, P., Law, P., Bugg, T. D. H., Biocatalytic conversion of lignin to aromatic dicarboxylic acids in Rhodococcus jostii RHA1 by re-routing aromatic degradation pathways, Green Chem. 17 (2015) 4974. doi: https://doi.org/10.1039/c5gc01347j

18. Kumar, M., Singh, J., Singh, M. K., Investigating the degradation process of kraft lignin by $\beta$-proteobacterium, Pandoraea sp. ISTKB, Environ. Sci. Pollut. Res. 22 (2015) 15690 .

doi: https://doi.org/10.1007/s11356-015-4771-5

19. Chen, Z., Wan, C., Biological valorization strategies for converting lignin into fuels and chemicals, Renew. Sust. Enery Rev. 73 (2017) 610. doi: https://doi.org/10.1016/j.rser.2017.01.166

20. De Gonzalo, G., Colpa, D. I., Habib, M. H. M., Fraaije, M. $W$. Bacterial enzymes involved in lignin degradation, J. Biotechnol. 236 (2016) 110.

doi: https://doi.org/10.1016/j.jbiotec.2016.08.011

21. Janabi, A. H. D., Kerkhof, L. J., McGuinness, L. R., Biddle, A. S., McKeeve, K. H., Comparison of a modified phenol/ chloroform and commercial-kit methods for extracting DNA from horse fecal material, J. Microbiol. Meth. 129 (2016) 14 doi: https://doi.org/10.1016/j.mimet.2016.07.019

22. Nakagawa, Y., Sakamoto, Y., Kikuchi, S., Sato, T., Yano, A., A chimeric laccase with hybrid properties of the parental Lentinula edodes laccases, Microbiol. Res. 165 (2010) 392. doi: https://doi.org/10.1016/j.micres.2009.08.006

23. Orth, A. B., Royse, D. J., Tien, M., Ubiquity of lignin-degrading peroxidases among various wood-degrading fungi, Appl. Environ. Microb. 59 (1993) 4017. doi: https://doi.org/10.1128/AEM.59.12.4017-4023.1993

24. Kapich, A. N., Prior, B. A., Botha, A., Galkin, S., Lundell, T., Hatakka, A., Effect of lignocellulose-containing substrates on production of ligninolytic peroxidases in sub- merged cultures of Phanerochaete chrysosporium ME-446, Enzyme Microb. Tech. 34 (2004) 187.

doi: https://doi.org/10.1016/j.enzmictec.2003.10.004

25. Shi, Y., Yan, X., Li, Q., Wang, X., Liu, M., Xie, S. S., Chai, L. Y., Yuan, J. S., Directed bioconversion of Kraft lignin to polyhydroxyalkanoate by Cupriavidus basilensis B-8 without any pretreatment, Process Biochem. 52 (2017) 238. doi: https://doi.org/10.1016/j.procbio.2016.10.004

26. Chang, Y. C., Choi, D., Takamizawa, K., Kikuchi, S., Isolation of Bacillus sp. strains capable of decomposing alkali lignin and their application in combination with lactic acid bacteria for enhancing cellulase performance, Bioresour. Technol. 152 (2014) 429.

doi: https://doi.org/10.1016/j.biortech.2013.11.032

27. Zhang, $W$., Xia, X., Isolation, kinetics, and performance of a novel phenol degrading strain, Chem. Biochem. Eng. Q. 33 (2019) 485. doi: https://doi.org/10.15255/CABEQ.2019.1685

28. Yan, S., Chai, L. Y., Tang, C., Yang, Z., Zhang, H., Chen, R., Chen, $Y$., Zheng, $Y$., Characterization and genomic analysis of kraft lignin biodegradation by the beta-proteobacterium Cupriavidus basilensis B-8, Biotechnol. Biofuel. 6 (2013) 1. doi: https://doi.org/10.1186/1754-6834-6-1

29. Kumar, A., Priyadarshinee, R., Singha, S., Sengupta, B., Roy, A., Dasgupta, D., Mandal, T., Biodegradation of alkali lignin by Bacillus flexus RMWW II: Analyzing performance for abatement of rice mill wastewater, Water Sci. Technol. 80 (2019) 1623. doi: https://doi.org/10.2166/wst.2020.005

30. Fang, X. X., Li, Q. M., Lin, Y. Q., Lin, X. L., Dai, Y. Q., Guo, Z. X., Pan, D. Z., Screening of a microbial consortium for selective degradation of lignin from tree trimmings, Bioresour. Technol. 254 (2018) 247 doi: https://doi.org/10.1016/j.biortech.2018.01.058

31. Raj, A., Chandra, R., Reddy, M. M. K., Purohit, H. J., Kapley, A., Biodegradation of kraft lignin by a newly isolated bacterial strain, Aneurinibacillus aneurinilyticus from the sludge of a pulp paper mill, World J. Microb. Biotechnol. 23 (2007) 793. doi: https://doi.org/10.1007/s11274-006-9299-x

32. Chen, Y. H., Chai, L. Y., Zhu, Y. H., Yang, Z. H., Zheng, Y., Zhang, $H$., Biodegradation of kraft lignin by a bacterial strain Comamonas sp. B-9 isolated from eroded bamboo slips, J. Appl. Microbiol. 112(5) (2012) 900. doi: https://doi.org/10.1111/j.1365-2672.2012.05275.x

33. Chandra, R., Bharagava, R. N., Bacterial degradation of synthetic and kraft lignin by axenic and mixed culture and their metabolic products, J. Environ. Biol. 34 (2013) 991. doi: https://doi.org/10.1111/gbi.12061

34. Jin, R., Identification and characterization of a fungal strain with lignin and cellulose hydrolysis activities, Afr. J. Microbiol. Res. 6 (2012) 6545 doi: https://doi.org/10.5897/AJMR12.476

35. Arun, A., Eyini, M., Comparative studies on lignin and polycyclic aromatic hydrocarbons degradation by basidiomycetes fungi, Bioresour. Technol. 102 (2011) 8063. doi: https://doi.org/10.1016/j.biortech.2011.05.077

36. Leonowicz, A., Cho, N. S., Luterek, J., Wilkolazka, A., Wojtas-Wasilewska, M., Matuzewska, A., Hofrichter, M., Wesenberg, D., Rogalski, J., Fungal laccase: Properties and activity on lignin, J. Basic Microbiol. 41 (2001) 185. doi: https://doi.org/ 10.1002/1521-4028(200107)41:3/4<18 5::aid-jobm $185>3.0 . c 0 ; 2-\mathrm{t}$

37. Wang, Y., Liu, Q., Yan, L., A novel lignin degradation bacterial consortium for efficient pulping, Bioresour. Technol. 139 (2013) 113. doi: https://doi.org/10.1016/j.biortech.2013.04.033 